\title{
Nicotine protects rat hypoglossal motoneurons from excitotoxic death via downregulation of connexin 36
}

\author{
Silvia Corsini ${ }^{1}$, Maria Tortora ${ }^{1}$, Rossana Rauti ${ }^{1}$ and Andrea Nistri ${ }^{\star * 1}$
}

Motoneuron disease including amyotrophic lateral sclerosis may be due, at an early stage, to deficit in the extracellular clearance of the excitatory transmitter glutamate. A model of glutamate-mediated excitotoxic cell death based on pharmacological inhibition of its uptake was used to investigate how activation of neuronal nicotinic receptors by nicotine may protect motoneurons. Hypoglossal motoneurons (HMs) in neonatal rat brainstem slices were exposed to the glutamate uptake blocker DL-threo- $\beta$ benzyloxyaspartate (TBOA) that evoked large $\mathrm{Ca}^{2+}$ transients time locked among nearby $\mathrm{HMs}$, whose number fell by about $30 \% 4 \mathrm{~h}$ later. As nicotine or the gap junction blocker carbenoxolone suppressed bursting, we studied connexin 36 (Cx36), which constitutes gap junctions in neurons and found it largely expressed by HMs. Cx36 was downregulated when nicotine or carbenoxolone was co-applied with TBOA. Expression of Cx36 was preferentially observed in cytosolic rather than membrane fractions after nicotine and TBOA, suggesting protein redistribution with no change in synthesis. Nicotine raised the expression of heat shock protein 70 (Hsp70), a protective factor that binds the apoptotic-inducing factor (AIF) whose nuclear translocation is a cause of cell death. TBOA increased intracellular AIF, an effect blocked by nicotine. These results indicate that activation of neuronal nicotinic receptors is an early tool for protecting motoneurons from excitotoxicity and that this process is carried out via the combined decrease in Cx36 activity, overexpression of Hsp70 and fall in AIF translocation. Thus, retarding or inhibiting HM death may be experimentally achieved by targeting one of these processes leading to motoneuron death.

Cell Death and Disease (2017) 8, e2881; doi:10.1038/cddis.2017.232; published online 15 June 2017

Amyotrophic lateral sclerosis (ALS) is characterized by motoneuron death in the brainstem and spinal cord. The etiopathology seems to involve a complex interplay among pathogenic factors such as glutamate-mediated excitotoxicity, reactive oxygen species (ROS) and mitochondrial dysfunction. ${ }^{1}$ The brainstem nucleus hypoglossus is often affected early, thus leading to dysarthria and dysphagia. ${ }^{2}$ Hypoglossal motoneurons (HMs) are very vulnerable because of their high basal intracellular $\mathrm{Ca}^{2+}$ (ref. 3), expression of $\mathrm{Ca}^{2+}$ permeable AMPA receptors ${ }^{4}$ and low levels of glutamate transporters. ${ }^{5}$ In ALS, these properties are exacerbated by impaired glutamate transport ${ }^{5,6}$ and increased level of glutamate in cerebrospinal fluid ${ }^{7}$ making excitotoxicity an important causative candidate. Motoneuron death shows patchy distribution and slow progression ${ }^{8}$ associated with muscle weakness and fasciculations. ${ }^{9}$

In the past few years, our laboratory has developed a simple in vitro model of excitotoxic stress applied to rat $\mathrm{HMs}^{10-12}$ It consists of mimicking the pathological process of motoneuron hyperexcitability and excitotoxicity in the nucleus hypoglossus through pharmacological inhibition of glutamate uptake with DL-threo- $\beta$-benzyloxyaspartate (TBOA). Salient characteristics of this model are generation of electrical bursting among HMs interconnected via gap junctions ${ }^{12}$ and slow onset of cell death ${ }^{11}$ via production of ROS and subsequent mitochondrial energy deficit in a subset of motoneurons. ${ }^{13,14}$ One essential property of HMs is their ability to generate 'group bursting' dependent on the membrane expression of gap junctions ${ }^{15,16}$ made by connexins, of which connexin 36 (Cx36) is highly represented in the nervous system. ${ }^{17,18}$ Gap junctions may also be due to pannexins, particularly pannexin 1 (Panx1), which share, with connexins, similar topology, permeability and gating. ${ }^{18,19}$ In case of cell stress, expression of connexins and pannexins may increase the probability of damage diffusion and cell death. ${ }^{17}$

We recently observed that the neuronal acetylcholine receptor (nAChR) agonist nicotine prevents $\mathrm{HM}$ dysfunction and associated cell death. ${ }^{13,14}$ Although these effects are dependent on $\mathrm{nAChR}$ activation, ${ }^{13}$ it seems likely that nicotine was simply a trigger for intracellular and network events contrasting excitotoxicity. Within this framework, on rat brainstem motoneurons nicotine induces early facilitation of glutamate release followed by depression together with enhancement of inhibitory neurotransmission. ${ }^{20}$ As a result of the complexity of the brainstem circuitry and its afferent projections, it is likely that the result of nicotine activity is the outcome of interplay among a variety of mechanisms. To better understand the action of nicotine, the present work investigated the functional topography of responsive neurons first and, subsequently, the processes of their modulation. One lead in this direction was provided by the report that in cultured endothelial cells nicotine downregulates connexins. ${ }^{21,22}$ Thus, we wondered if a similar process could account for neuroprotection of HMs. To this aim, we studied how nicotine could modulate $\mathrm{Ca}^{2+}$ transients, $\mathrm{Cx} 36$ and Panx1, and compared it with the effects of the gap junction blocker carbenoxolone. ${ }^{23}$ In

\footnotetext{
${ }^{1}$ Department of Neuroscience, International School for Advanced Studies (SISSA), Trieste, Italy

*Corresponding author: A Nistri, Department of Neuroscience, International School for Advanced Studies (SISSA), via Bonomea 265, Trieste 34136 Italy. Tel: +39 403787 718; Fax: +39 40 3787702; E-mail: nistri@ sissa.it

Received 01.12.16; revised 21.4.17; accepted 26.4.17; Edited by A Verkhratsky
} 

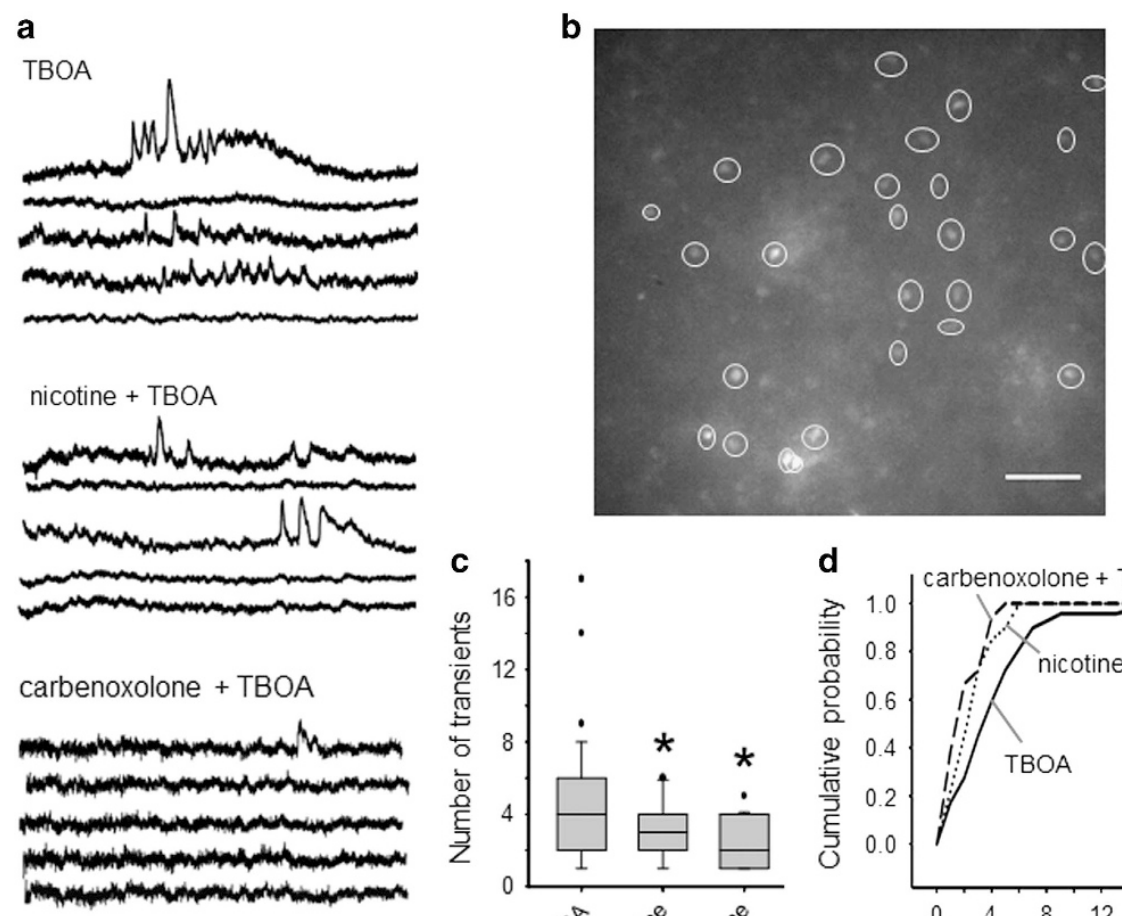

$5 \% \Delta \mathrm{F}_{0} / \mathrm{F}_{20 \mathrm{~s}}$
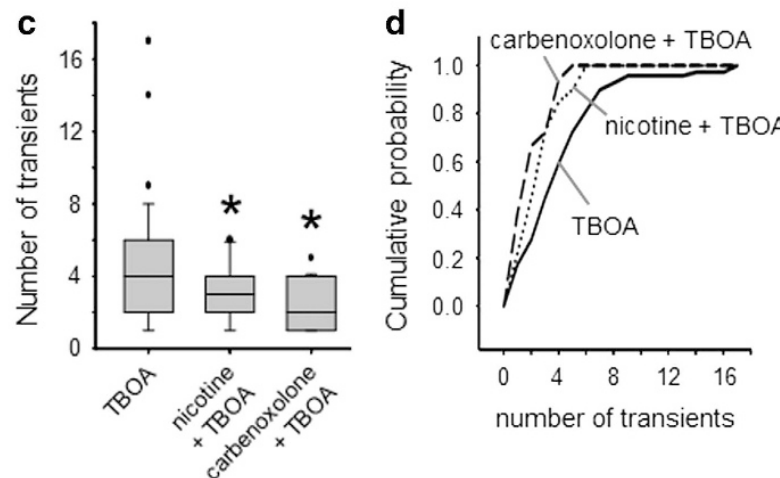

Figure $1\left[\mathrm{Ca}^{2+}\right]_{\mathrm{i}}$ transients evoked by TBOA. (a) Example of records of $\left[\mathrm{Ca}^{2+}\right]_{i}$ changes simultaneously taken from five HMs in the same slice preparation in presence of TBOA (50 $\mu \mathrm{M}$; top), nicotine $(10 \mu \mathrm{M})+$ TBOA (middle), or carbenoxolone $(200 \mu \mathrm{M})+$ TBOA (bottom). (b) Example of slice preparation containing HMs. Each ROI indicates a different cell used for analysis. Bar $=50 \mu \mathrm{m}$. (c) Box plot of the number of transients evoked during the different treatment listed above; nicotine or carbenoxolone co-application with TBOA significantly reduces the number of the events (Kruskal-Wallis one-way ANOVA: ${ }^{*} P=0.001$; Dunn's method: $P<0.05$ for TBOA versus nicotine + TBOA, and for TBOA versus carbenoxolone + TBOA; $n$ : 69, TBOA; 40, nicotine + TBOA; 18, carbenoxolone + TBOA; $N=5$ ). (d) When TBOA is applied alone, the cumulative probability line (solid line) is significantly shifted to the right compared with nicotine + TBOA (dotted line) or carbenoxolone + TBOA (dashed line; Kolmogorov-Smirnov statistic test: $P \leq 0.001$ for TBOA versus nicotine + TBOA, and $P \leq 0.001$ for TBOA versus carbenoxolone + TBOA)

analogy with previous reports, ${ }^{24,25}$ we used expression of heat shock protein 70 (Hsp70) and apoptosis-inducing factor (AIF) as indices of cell protection or death, respectively.

\section{Results}

Network distribution of $\mathrm{Ca}^{2+}$ signals induced by TBOA. TBOA $(50 \mu \mathrm{M})$ induces bursting activity in about $50 \%$ of $\mathrm{HMs}^{12,13}$ with large inward currents translated into strong intracellular $\mathrm{Ca}^{2+}$ transients. ${ }^{26}$ This study investigated $\left[\mathrm{Ca}^{2+}\right]_{\mathrm{i}}$ changes in the hypoglossal nucleus (Figures $1 \mathrm{a}, \mathrm{b}$ and Supplementary Movies 1-3) to monitor excitation spread. Thus, we performed continuous imaging (10 min) of $\left[\mathrm{Ca}^{2+}\right]_{i}$ transients as shown in Figure $1 \mathrm{~b}$ and Supplementary Movies 1-3, in which about $30 \mathrm{HMs}$ for each slice were recorded during application of TBOA. Figure 1a shows representative examples (taken from five $\mathrm{HMs}$ ) recorded in the presence of TBOA alone (top records; Supplementary Movie 1), or co-applied with nicotine $(10 \mu \mathrm{M})$ (Figure 1a middle; Supplementary Movie 2), or with carbenoxolone $(200 \mu \mathrm{M})$ (Figure 1a bottom; Supplementary Movie 3). TBOA induced transients in about $50 \%$ of $\mathrm{HMs}(50 \pm 8 \%, n=5$ slices), a value reduced to $36 \pm 14 \%$ ( $n=5$ slices) in presence of nicotine, and to $14 \pm 7 \%$ when carbenoxolone was coapplied ( $n=5$ slices). On average, nicotine or carbenoxolone significantly decreased the number of transients evoked by TBOA (Figure 1c; $P=0.001)$ as they fell from $4.4 \pm 0.4(n=69$ $\mathrm{HMs})$ to $2.8 \pm 0.2(P<0.05, n=40 \mathrm{HMs})$ in presence of nicotine, or to $2.3 \pm 0.3(P<0.05, n=18 \mathrm{HMs})$ with carbenoxolone co-application. However, neither nicotine nor carbenoxolone changed the basal level of $\left[\mathrm{Ca}^{2+}\right]_{i}$ at $10 \mathrm{~min}$. Figure 1d shows a plot of the number of transients against cumulative probability. Thus, the plot for nicotine or carbenoxolone co-application is significantly shifted to the left $(P \leq 0.001$ for TBOA, solid line versus nicotine + TBOA, dotted line; and $P \leq 0.001$ for TBOA versus carbenoxolone + TBOA, dashed line), demonstrating increased probability to observe fewer events than in the presence of TBOA alone.

As a result of the scattered onset of $\left[\mathrm{Ca}^{2+}\right]_{i}$ transients (Supplementary Movies 1-3), we studied whether topographical distance between two motoneurons was predictive of the closely spaced activity. Thus, Figure 2 compares the interneuronal distance with the latency between the first calcium transient of each cell pair as exemplified in Figure 2a in which the long interval between transients indicates lack of coupling. The top plot (Figure 2b), which refers to TBOA-treated cells only, shows how the latency between transients was significantly related to their distance $(\rho=0.30, P<0.001)$ and that the vast majority of latency values were below $100 \mathrm{~s}$. 


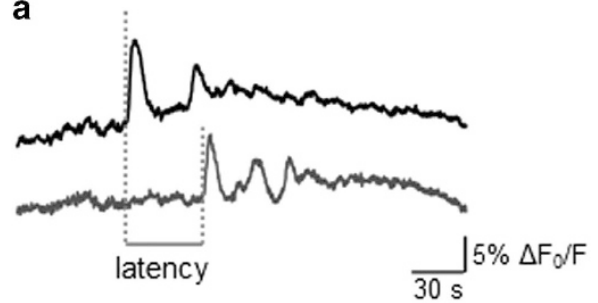

b

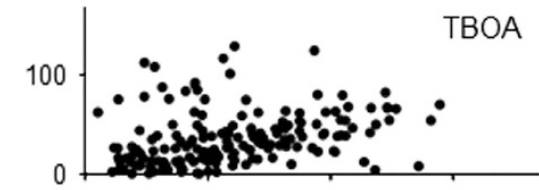

C

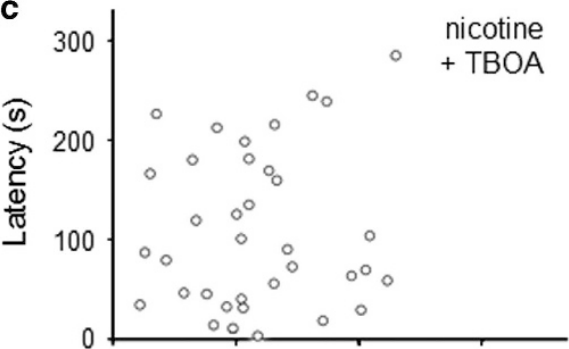

d

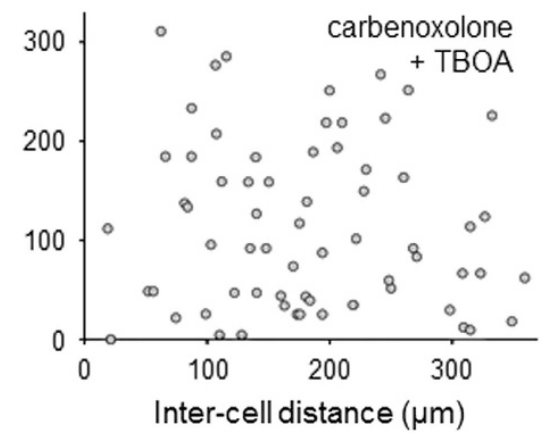

Figure 2 Topographic distribution of $\mathrm{Ca}^{2+}$ transients according to inter-cell distance. (a) Example of latency analysis taken as interval between $\mathrm{Ca}^{2+}$ transient onset in two nearby HMs. (b-d) Inter-cell latency scatter plots in presence of TBOA $(50 \mu \mathrm{M}$; (b), or nicotine $(10 \mu \mathrm{M})+\mathrm{TBOA}(\mathbf{c})$ or carbenoxolone $(200 \mu \mathrm{M})+\mathrm{TBOA}(\mathrm{d})$. Each data point represents the latency value calculated for a pair of cells. For data points shown in $\mathbf{b}$, a significant linear correlation $(\rho=0.30, P<0.001)$ between signal latency and cell distance was observed with the analysis of deviance (see Materials and Methods section) in which the regression line for the plot of latency (taken as y) is equal to $21.08+0.13$ inter-cell distance (taken as $\mathrm{x}$ ): this result differs in a significant manner $(P<0.001)$ from the null linear model, that is, the mean value latency $=36.60$. Therefore, the regression line appears to be the minimal adequate model to establish that distance has an effect on latency in a statistical sense

Conversely, when nicotine or carbenoxolone was co-applied with TBOA (Figures 2c and d), the plots comprised a cloud of widely scattered points with latency values larger than $200 \mathrm{~s}$ even for closely located HMs. These data demonstrated the asynchronous occurrence of $\left[\mathrm{Ca}^{2+}\right]_{i}$ changes when nicotine or carbenoxolone were co-applied.

Nicotine or carbenoxolone modulates Cx36 expression. As HM bursting is supported by a variety of mechanisms including gap junctions, ${ }^{15,16,26,27}$ the above results raised the hypothesis that nicotine (like carbenoxolone) may impair intercellular communication via Cx36 and Panx1. As mitochondrial dysfunction and motoneuron death are observed after 4-h treatment with TBOA $^{13}$ we evaluated $\mathrm{Cx36}$ expression (Figures $3 a$ and $b$; red) in relation to immunoreactivity of single HMs (identified with SMI 32 immunostaining; green). DAPI was used for nuclear staining (blue). In accordance with previous studies, ${ }^{28,29} \mathrm{Cx36}$ immunoreactivity was distributed through the soma of $\mathrm{HMs}$ as shown in Figure $3 \mathrm{a}$ (middle column) and quantified in Figure $3 \mathrm{~b}$. There was also weak staining of the nucleus in accordance with the report by Belluardo et al. ${ }^{30}$ who have detected nuclear $\mathrm{Cx36}$ in rat brain neurons.

In the present experiments, the Cx36 signal was not significantly altered by TBOA alone in the cells that remained after the excitotoxic stimulation, whereas the motoneuronal number after TBOA (Figure 3c) fell by approximately $30 \%$. When nicotine was co-applied with TBOA, the Cx36 immunoreactivity was significantly decreased (Figures $3 a$ and b) and the average number of motoneurons was similar to sham (Figure 3c). An analogous result was observed when carbenoxolone was co-applied with TBOA (Figures 3a-c). Nicotine per se did not change the average Cx36 signal (Figure $3 a$ and $b$ ) or motoneuron survival (Figure 3c). ${ }^{13}$

To further investigate the amount of $\mathrm{Cx} 36$ expressed under various experimental conditions, western blot experiments were performed as depicted in Figure 4 using brainstem tissue blocks in order to collect a sufficient amount of protein. Even if the nucleus hypoglossus represents only a minor region of this tissue, this approach was earlier useful to detect changes in gene profiling, protein synthesis and expression, and mitochondrial energy production ${ }^{13,14}$ which, although cannot be directly attributed to HMs (or other brainstem motoneurons), yet they provide an index of the metabolic state of the network and of any ongoing neuroprotective process.

Evaluation of Cx36 total lysate (approximately $36 \mathrm{kDa}$ ) samples confirmed unchanged protein quantity after 4-h treatment with TBOA $(0.99 \pm 0.07, n=9$ brainstems $)$ or nicotine $(0.94 \pm 0.07, n=6$ brainstems; Figure $4 a)$. In support of the immunohistochemical data (Figures $3 a$ and $b$ ), we observed that, when samples were treated with nicotine + TBOA or carbenoxolone + TBOA, Cx36 expression was significantly reduced to $0.89 \pm 0.07$ ( $n=9$ brainstems) or $0.82 \pm 0.08$ ( $n=5$ brainstems; $P=0.015$ among groups), respectively. We further explored the distribution of Cx36 in membrane and cytoplasmic compartments. In the case of nicotine exposure, there was a small, yet significant decrease in Cx36 membrane expression (Figure 4b; $P=0.008$ for sham versus nicotine; $n=5$ brainstems) concomitant with a corresponding increase in the cytoplasmic fraction (Figure 4c; $P<0.05$ for sham versus nicotine; $n=5$ brainstems). The fall in membrane expression of Cx36 was intensified when nicotine was co-applied with TBOA (Figure $4 \mathrm{~b} ; P=0.016$ for sham versus nicotine + TBOA; $n=5$ brainstems) in association with a significant rise in the cytoplasmic expression (Figure 4c; $P<0.05$ for sham versus nicotine + TBOA; $n=5$ brainstems). Interestingly, no compartmental expression was modified by TBOA alone, perhaps suggesting that the manifestation of the action of this drug required an unchanged Cx36 expression. These effects of Cx36 compartmentalization were not due to changes in its synthesis as qPCR 
a
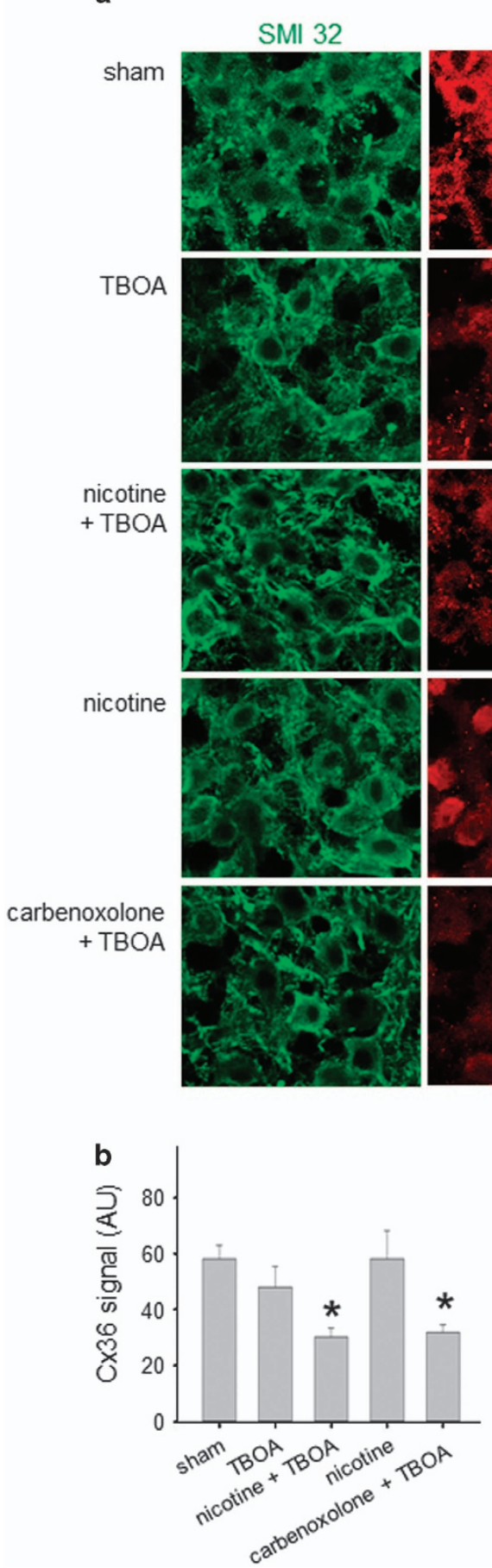

SMl $32+$ Cx36 + DAPI
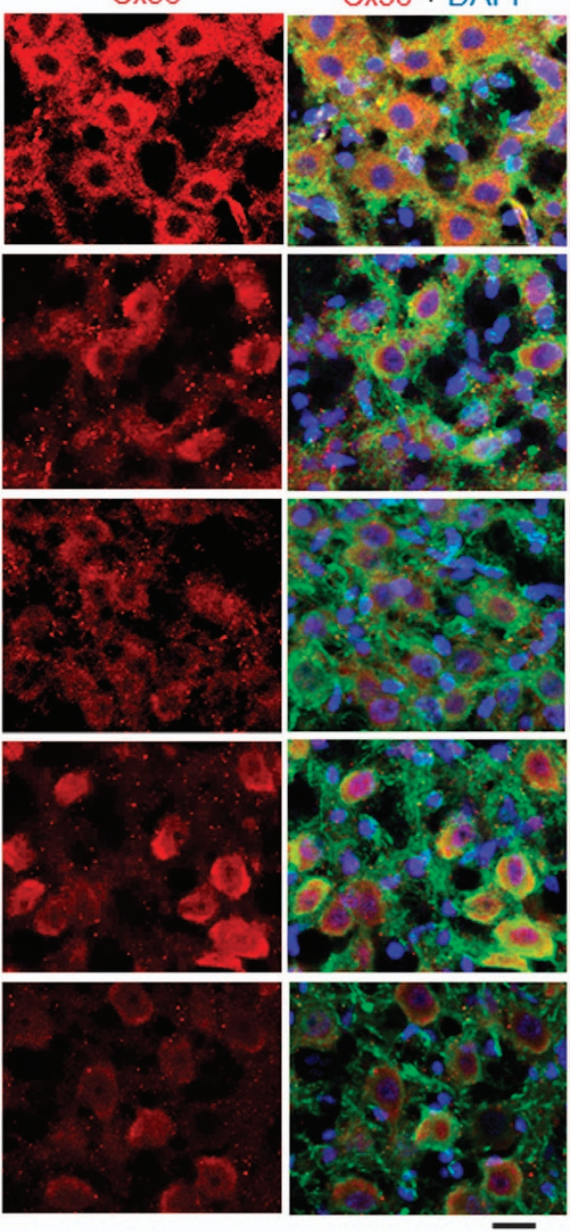

$25 \mu \mathrm{m}$

C

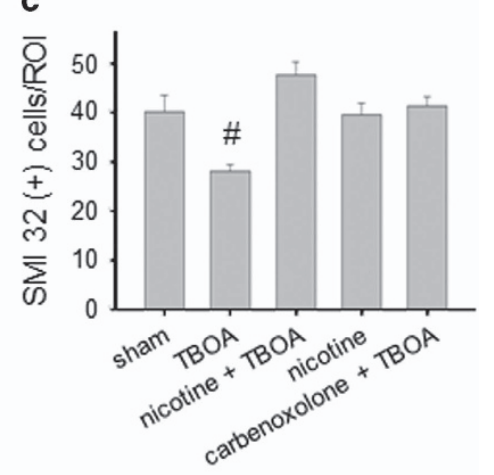

Figure 3 Nicotine and carbenoxolone induce significant reduction in Cx36 expression. (a) Example of HMs after 4-h incubation in Krebs (sham), TBOA, nicotine + TBOA, nicotine, or carbenoxolone + TBOA. HMs were labeled with SMI 32 (green pseudocolor; left column), as motoneuronal marker, or Cx36 (red pseudocolor; middle column). The right column shows merged images where DAPI (blue pseudocolor) is used to visualize nuclei. (b) Histograms quantify the Cx36 signal decrease after $4 \mathrm{~h}$ of nicotine + TBOA (Kruskal-Wallis one-way ANOVA: $P=0.005$ among groups; Dunn's method: ${ }^{*} P<0.05$ for sham versus nicotine + TBOA) or carbenoxolone + TBOA treatments (Dunn's method: ${ }^{*} P<0.05$ for sham versus carbenoxolone + TBOA). Cx36 mean signal (AU): $58 \pm 4.9$, sham $(n=10, N=3) ; 48 \pm 7.2$, TBOA $(n=15, N=4) ; 30 \pm 3.4$, nicotine + TBOA $(n=14$, $N=3) ; 58 \pm 10$, nicotine $(n=8, N=3) ; 32 \pm 2.8$, carbenoxolone + TBOA $(n=11, N=4)$. (c) Plot indicates significant HM loss after TBOA treatment, an effect fully prevented by nicotine or carbenoxolone co-application (HMs: $40 \pm 3$, sham; $28 \pm 1$, TBOA; $48 \pm 3$, nicotine + TBOA; $40 \pm 2$, nicotine; $41 \pm 2$, carbenoxolone + TBOA; Kruskal-Wallis one-way ANOVA: $P=0.001$ among groups; Holm-Sidak method: ${ }^{\#} P<0.05$ for TBOA versus sham, nicotine + TBOA, nicotine, or carbenoxolone + TBOA) 

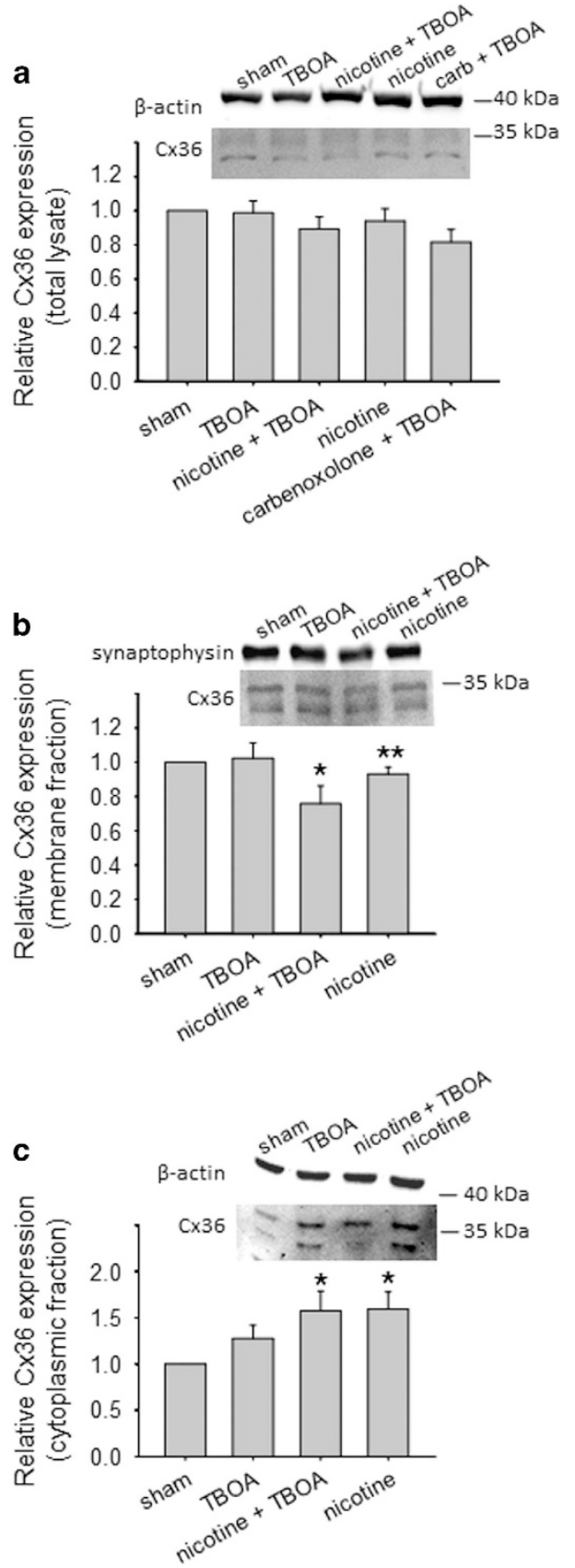

Figure 4 Brainstem Cx36 expression decreases because of nicotine or carbenoxolone application. (a) Example of western immunoblotting (top) showing the expression of $\mathrm{C} \times 36$ in brainstems incubated for $4 \mathrm{~h}$ in Krebs, or treated with TBOA, nicotine + TBOA, nicotine, or carbenoxolone + TBOA. Histograms (bottom) quantifying the significantly decreased $\mathrm{C} \times 36$ levels after treatment with nicotine + TBOA $(\mathrm{n}, N=9)$ or carbenoxolone + TBOA (n, $N=5$; Kruskal-Wallis one-way ANOVA: $P=0.015$ among groups). (b and $\mathbf{c}$ ) Example of western blot (top) showing Cx36 expression in membrane (b) or the cytoplasmic (c) fractions of samples treated as described above. Histograms illustrate how nicotine alone or co-applied induces a significant decrease of Cx36 expression in the membrane pool (b, bottom; Kruskal-Wallis one-way ANOVA: $P=0.069$ among groups; Mann-Whitney test: ${ }^{*} P=0.016$ for sham versus nicotine $+\mathrm{TBOA}$ and ${ }^{* \star} P=0.008$ for sham versus nicotine; $\left.\mathrm{n}, N=5\right)$ and an increase in the cytoplasmic one (c, bottom; Kruskal-Wallis one-way ANOVA: $P=0.014$ among groups; Tukey test: ${ }^{*} P<0.05$ for sham versus nicotine + TBOA, and for sham versus nicotine $n, N=5$ ) experiments showed no alteration in the $\mathrm{C} \times 36$ gene product (Figure 5a; $P=0.21$ among groups; $n=6$ brainstems).

Hsp70 and AIF contrasting expression in HMs. In case of excitotoxicity, motoneuronal survival may depend on the relative intracellular expression of Hsp70 and AIF with cellprotecting or cell-damaging properties, respectively. ${ }^{24,25}$ Figures $5 \mathrm{~b}$ and $\mathrm{c}$ show that, after TBOA or nicotine treatment, Hsp70 expression was unchanged compared with basal sham conditions. When nicotine and TBOA were co-applied, Hsp70 expression was significantly enhanced $(P=0.027$ among groups; $P<0.05$ for sham versus nicotine + TBOA; $n=5$ brainstems). Thus, during excitotoxic stimulation, application of nicotine enhanced Hsp70 expression, thereby strengthening the neuroprotective processes of motoneurons. In fact, protection of motoneurons from excitotoxicity depends to a large extent on the binding by Hsp70 of AIF, a mitochondrial factor released by metabolically damaged motoneurons. ${ }^{24,25}$ When, during excitotoxicity, Hsp70 expression is insufficient to bind AIF, the latter migrates to the cell nucleus and inactivates DNA. ${ }^{31} \mathrm{We}$, therefore, studied immunohistochemical expression of AIF when TBOA was applied alone or together with nicotine. Figure $6 a$ shows examples of AIF immunoreactivity increased after TBOA administration with broad distribution within nuclear (delineated by the blue line in Figure $6 b$ for DAPI staining) and non-nuclear compartments as indicated by the line scan red trace that had higher value throughout (Figure 6b; note different ordinate scale for the various treatment protocols). Vice versa, the level of AIF was low in the presence of nicotine with or without TBOA (Figure $6 b$ ), suggesting that nicotine kept the AIF level at sham-like condition. These data are quantified in the bar graph of Figure $6 \mathrm{c}$ in which the average fluorescence signal (AU) of AIF in basal condition was $16.1 \pm 3.2$ ( $n=9$ slices) and significantly increased to $60 \pm 7.8(P<0.05, n=19$ slices $)$ after TBOA exposure, whereas it was low when nicotine was co-applied with TBOA ( $n=16$ slices). It should be noted that nicotine ( $n=6$ slices) per se left unchanged the AIF immunoreactivity compared with sham.

Unchanged expression of Panx1. We sought to understand whether nicotine or carbenoxolone could change other proteins such as Panx1 reputed to make gap junctions. To this end, immunohistochemical and western blot experiments were performed as illustrated in Figures 7a-c. Hence, Panx1 immunoreactivity was readily detected in $\mathrm{HMs}$ as depicted in Figure $7 \mathrm{a}$ and remained unchanged following TBOA with or without nicotine protocols (Figure 7b). Similarly, Panx1 protein expression was very similar among all these treatments, indicating that Panx1 was not involved in nicotine neuroprotection at least within the 4-h experimental timeframe.

\section{Discussion}

The novel finding of this study was the demonstration that, during an excitotoxic stimulus, nicotine perturbed the emergence of coordinated $\mathrm{Ca}^{2+}$ transients, decreased the 

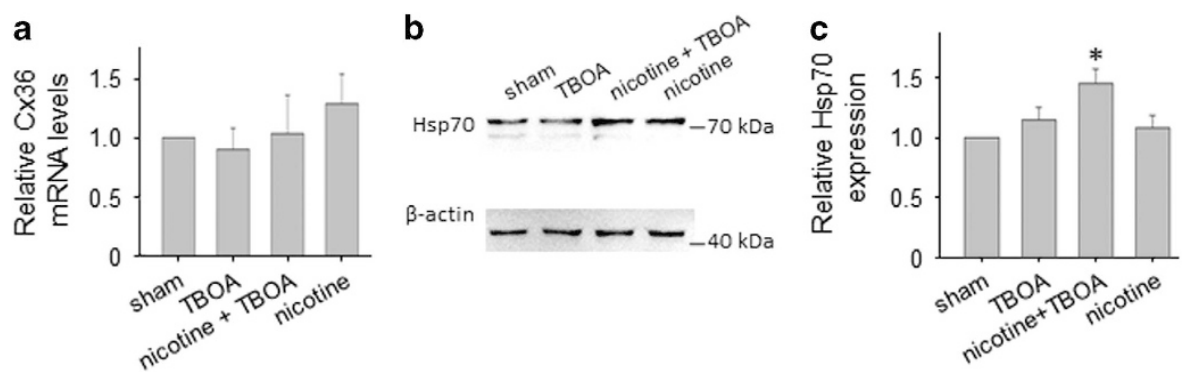

Figure 5 Cx36 mRNA levels and Hsp70 expression. (a) Plot illustrating unchanged values of Cx36 mRNA levels among different treatments. Fractional Cx36 expression (AU): $1 \pm 0.0$, sham; $0.9 \pm 0.2, T B O A ; 1 \pm 0.3$, nicotine + TBOA; $1.3 \pm 0.2$, nicotine $(n, N=6)$. (b) Example of Hsp70 immunoblotting. (c) Histogram quantifying the significant increase of Hsp70 expression after nicotine + TBOA treatment (Kruskal-Wallis one-way ANOVA: $P=0.027$ among groups; Holm-Sidak method: ${ }^{*} P<0.05$ for sham versus nicotine + TBOA; $\mathrm{n}, \mathrm{N}=5)$

a

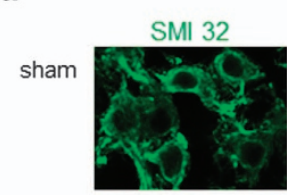

TBOA

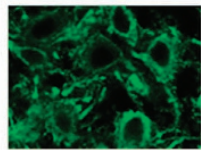

nicotine
+ TBOA

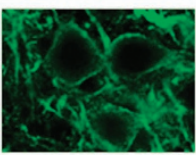

nicotine

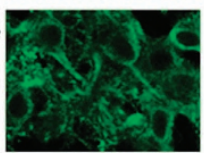

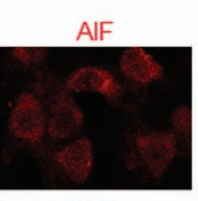
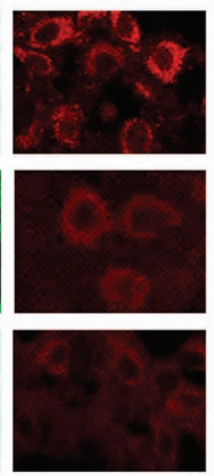

AlF + SMI 32 $+\mathrm{DAPI}$
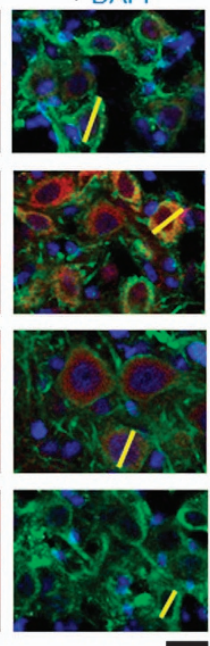

$25 \mu \mathrm{m}$

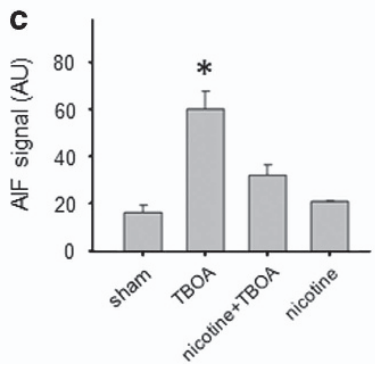

b
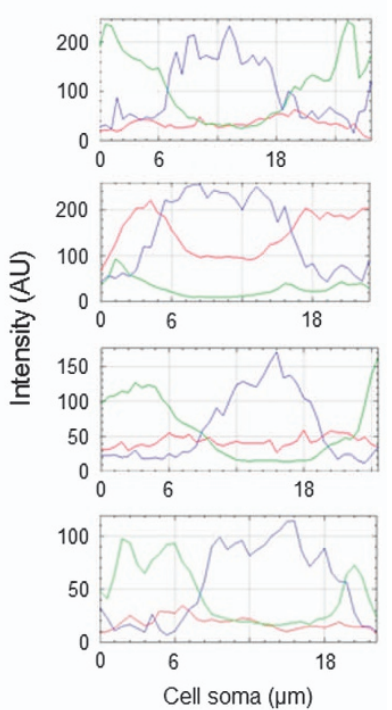

Figure 6 Expression of AIF in HMs. (a) Confocal images of SMI 32 (left; green), AIF (middle; red) and DAPI (blue; merged image, right) of motoneurons in control condition or after TBOA $(50 \mu \mathrm{M})$, nicotine $(10 \mu \mathrm{M})+$ TBOA, or nicotine alone. (b) Line scan analysis for the cells indicated by the bars in a. Nuclear area is delimited by the strong DAPI distribution. Note different ordinate calibrations. The large rise in AIF with TBOA is prevented by nicotine. (c) Histograms show average AIF intensity signal in cell soma. There is no difference between sham $(n=9, N=4)$ and nicotine $(n=6, N=3)$ data. TBOA treatment $(n=19, N=7)$ induces a large increase in AlF expression (*Kruskal-Wallis one-way ANOVA: $P<0.001$; Dunn's method: $P<0.05$ for TBOA versus sham and TBOA versus nicotine). Nicotine + TBOA $(n=16, N=5)$ elicits a comparatively smaller increase in AlF

expression of $\mathrm{Cx36}$ at membrane level, enhanced the expression of $\mathrm{Hsp} 70$ while diminishing the one of AIF. These data were critical components of the neuroprotective action by this alkaloid. As many effects of nicotine were replicated by carbenoxolone, it is likely that inhibition of $\mathrm{Cx} 36$ was essential to uncouple motoneurons from their collective bursting behavior that was prodromic to cell distress and death.
Motoneurons wired together, die together. Inhibition of glutamate uptake recruits clusters of motoneurons in group bursting that, if it continues unabated, will lead to significant neuronal death. ${ }^{12}$ As our recent work indicates that nicotine largely suppresses bursting, ${ }^{13}$ we investigated how this phenomenon was expressed within the HM population (recorded as $\mathrm{Ca}^{2+}$ transients) and its spatio-temporal 
a
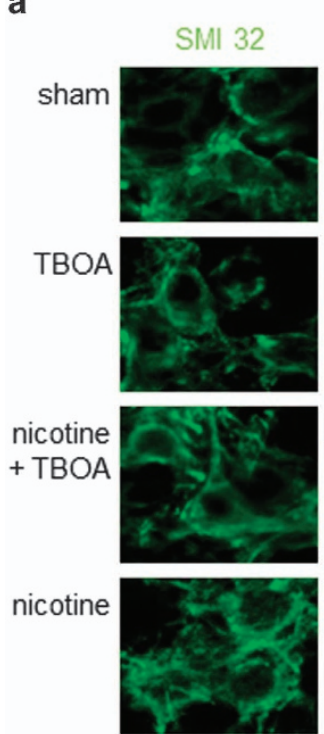
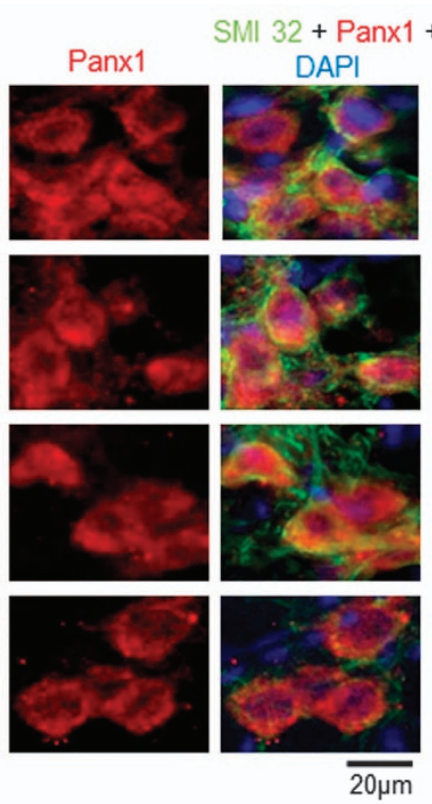

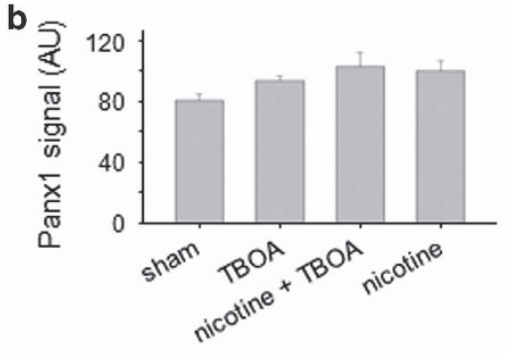

c
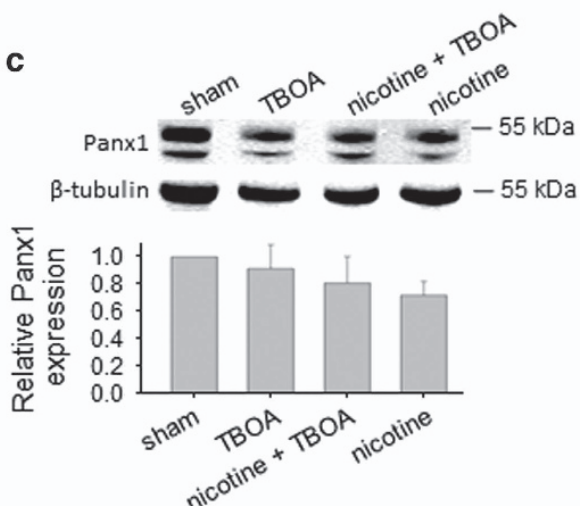

Figure 7 Panx1 expression remains unchanged. (a) Example of HMs after 4-h incubation in Krebs (sham), TBOA, nicotine + TBOA, or nicotine, labeled with the neuronal marker SMI 32 (left column; green), or Panx1 (middle column; red). Merged images are shown on the right column where DAPI (blue) is used as nuclear marker. (b) Histograms quantifying unchanged levels of Panx1 among the treatments described above. (c) Example of western immunoblotting (top) showing the unchanged expression of Panx1 in brainstems incubated as described above

correlation. Neighboring HMs often generated time-correlated $\mathrm{Ca}^{2+}$ transients suggesting their functional ensemble. It has been demonstrated that carbenoxolone acting as a pharmacological blocker of gap junctions, inhibits motoneuron synchronization in vertebrates and invertebrates. ${ }^{32,33}$ Thus, following application of carbenoxolone as well as nicotine, bursting became sparse and, importantly, this event was followed by significant protection of HMs from death. This realization implies that the severity of damage was perhaps dependent on the collective activation and recruitment of clusters of HMs into pathological discharges, and led us to study the role of gap junctions (known to exist among HMs; $15,16)$ mediated by Cx36 in this process.

Even if carbenoxolone is not a very specific blocker of gap junctions, the salient contribution by these structures to the collective bursting behavior and their inhibition by nicotine were validated with immunohistochemistry data as shown in Figures $3 a$ and $b$.

Connexins and cell death. Cx36 is the most prevalent gap junction protein expressed by neurons. ${ }^{17,18}$ It electrically couples neighboring cells by allowing transcellular communication and exchange of $\mathrm{Ca}^{2+}, \mathrm{Na}^{+}, \mathrm{K}^{+}$, and small $(<1-$ $1.5 \mathrm{kDa}$ ) hydrophilic molecules. ${ }^{18,34}$ Many factors regulate the activity of gap junction channels, including changes in voltage, $\left[\mathrm{Ca}^{2+}\right]_{i}, \mathrm{pH}^{35}$ connexin phosphorylation ${ }^{35,36}$ and ROS $^{37}$ In the past few years, many other components of intra/extracellular signaling have been associated with plasma membrane hemichannels such as facilitation of glutamate release from astrocytes ${ }^{38}$ and apoptosis. ${ }^{34}$ Indeed, gap junction-related apoptosis has been demonstrated by carbenoxolone-mediated prevention, ${ }^{39}$ and by the spreading of death signals within a cell cluster via gap junctions. ${ }^{39,40}$ This mode of propagation from injured to uninjured close neighbor cells is classified as bystander killing (the "kiss of death') ${ }^{17,34}$ An interaction among connexins and mitochondrial AIF in cardiomyocytes has been described with potential effects on mitochondrial respiration and ROS signaling. ${ }^{41}$ Whether this process could also occur in motoneurons remained unclear.

During NMDA receptor-mediated excitotoxicity, a strong reduction in neuronal death of cultured cortical neurons is obtained when $\mathrm{Cx} 36$ is pharmacologically blocked or genetically ablated, indicating that the expression level of Cx36 critically modulates neuronal death. ${ }^{27,42}$ Thus, the observation of basal expression of $\mathrm{C} \times 36$ by HMs made this protein a likely candidate in the excitotoxic cell death. It was of interest that, following glutamate uptake block and loss of a number of HMs, surviving cells did not show impaired Cx36 expression, alluding to the possibility that these cells had relied on certain intrinsic mechanisms to withstand the injury process.

Nicotine prevents HM excitotoxic death via Cx36 downregulation. In endothelial cell cultures, nicotine, via membrane ACh receptors, downregulates various connexins through intracellular pathways ${ }^{21,22}$ that impact their turnover. $^{22}$ In excitotoxic stress, we actually detected a fall in Cx36 immunoreactivity of HMs when nicotine (or carbenoxolone) was applied with TBOA, a result that was accompanied by no significant loss of HMs. Although nicotine can decrease excitatory synaptic transmission on $\mathrm{HMs},{ }^{13,20}$ the analogy with the effects by carbenoxolone and the 
downregulated immunopositivity of $\mathrm{Cx36}$ suggested that $\mathrm{Cx36}$ were important targets to restrain excitotoxicity. Previous studies have shown that the turnover of Cx36 is rapid $(3 \mathrm{~h}),{ }^{43}$ a result consistent with fast changes in protein expression without changes in Cx36 synthesis as shown by the negative qPCR data of the present experiments. Previous studies have demonstrated an early decrease in Cx43 expression by carbenoxolone. $^{44}$ Thus, it is feasible that blocking Cx36 directly with carbenoxolone or via intracellular signaling with nicotine led to decreased immunosignal of this protein at HM level because degradation was enhanced and/or replenishment impaired. In the case of nicotine, one parsimonious hypothesis is that this drug delayed Cx36 transportation from intracellular stores to the plasma membrane so that ongoing Cx36 degradation could not be efficiently compensated. Our view is consistent with the notion of nicotine uncoupled cells via increased proteolysis of connexins. ${ }^{22}$

Circumstantial evidence was sought with tissue fractionation experiments in which we sought the relative distribution of Cx36 among membrane and cytosolic fractions. Despite the limitation inherent in the use of brainstem tissue blocks containing a heterogeneous cell population, we detected a significant decrease in the $\mathrm{Cx} 36$ membrane fraction together with a notable rise in its cytoplasmic fraction that also comprises contributions from intracellular stores. These data implied that the expression and perhaps the function of $\mathrm{Cx36}$ at membrane level were impaired with nicotine application. Although the present data cannot, of course, be attributed to discrete changes in HMs alone because of the use of brainstem tissue, they allowed us to point to $\mathrm{Cx36}$ as an important target for nicotine neuroprotection: should this process extend to other brainstem neurons (or glia), it may reinforce the widespread impact of nicotine effect against excitotoxicity. Our model also indicated that the effect by nicotine had a degree of specificity as Panx1 expression was unchanged by nicotine. We cannot, however, rule out that the long life-cycle of Panx $1^{45}$ had precluded detecting a later alteration following nicotine application.

Nicotine modulated Hsp70 expression as a gateway to cell survival against AIF-mediated death. One further result of interest was the observation that nicotine and TBOA application evoked a significant increase in Hsp70 expression, whereas nicotine or TBOA alone did not change this protein. As the intracellular expression of $\mathrm{Hsp} 70$ is an important biomarker of the ability of motoneurons to resist to excitotoxicity, ${ }^{24}$ we surmise that surviving cells had an adequate Hsp70 expression although these data were obtained from brainstem tissue rather than single HMs. The perturbation triggered by TBOA plus the effects of nicotine probably synergized to raise Hsp70 expression and extend neuroprotection. These observations, therefore, provided an interesting clue to further explore the mechanism of nicotine neuroprotection. Our view was in line with reports of nicotine ability to enhance Hsp70 expression in lung vessels and ovarian tissue culture, ${ }^{46,47}$ and to block AIF lethal translocation into the nucleus. ${ }^{31}$ The immunofluorescent data showed that, at HM level, TBOA clearly enhanced the expression of AIF, a factor released by distressed mitochondria, and that this biomarker was distributed throughout the motoneuron
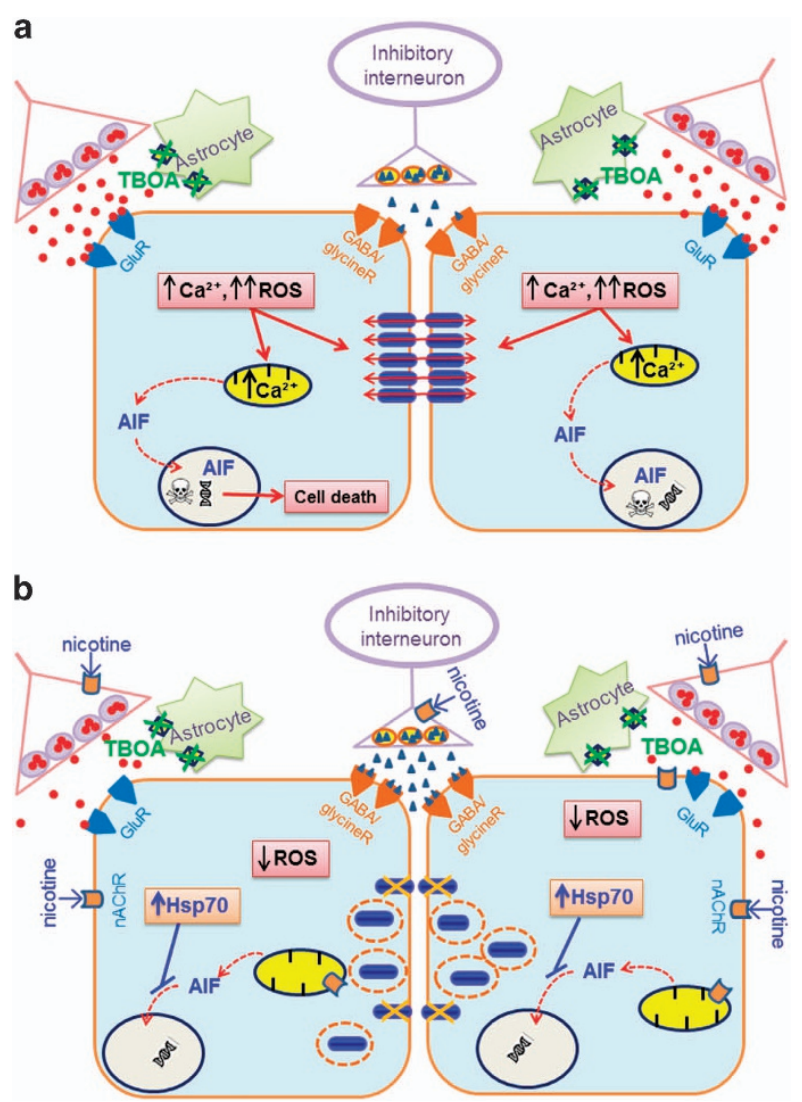

Figure 8 Idealized diagram to account for the toxic effects by TBOA and their antagonism by nicotine on HMs. (a) In the presence of TBOA, glutamate (filled red circles) released from presynaptic terminals acts on glutamatergic receptors to depolarize HMs. TBOA-mediated inhibition of glutamate uptake by astrocytes leads to intensification of glutamate effects with build-up of intracellular free $\mathrm{Ca}^{2+}$, which acts on mitochondria and favors production of ROS, release of AIF and DNA damage. This process is greatly amplified by the bidirectional (red arrows) operation of gap junctions (Cx36; filled blue cylinders) that spread and recruit HMs into a hyperexcitable state with deleterious consequences on cell survival. (b) In the presence of nicotine, the neurotoxic effect of TBOA is largely attenuated. Nicotine exerts multiple effects via nAChRs located on presynaptical terminals (with consequent decrease in glutamate release, and increase in the inhibitory response), $\mathrm{HM}$ membrane and even mitochondria. Through these effects, nicotine strongly decreases the motoneuron coupling via gap junctions through redistribution of Cx36 subunits, therefore disjoining motoneurons from their collective excitatory behavior. Our hypothesis is that this process is accompanied by inhibition of Cx36 activity, reduction in production of ROS and facilitation of the effect of Hsp70 to sequester AIF and prevent its nuclear migration. For references, see text

including its nucleus. Co-application of TBOA and nicotine normalized the rise in AIF expression and restituted shamlike condition, suggesting that the effect of this death factor was inhibited likely as a consequence of the raised Hsp70 expression in the cytoplasm. These results indicate that neuroprotection by nicotine was, at least in vitro, more systematic than the effect produced for example by pharmacological depression of glutamate release with riluzole. ${ }^{11} \mathrm{We}$ propose that the additional target of Cx36 uncoupling by nicotine is important to confer prevention of excitotoxicity.

A scenario for motoneuron protection by nicotine. Figure 8 depicts an idealized diagram to account for the process of $\mathrm{HM}$ death evoked by glutamate uptake block and 
the intervention levels exerted by nicotine. Excitotoxicity, induced by block of excitatory amino-acid transporters, ${ }^{48}$ severely damages motoneurons by excessive glutamate receptor stimulation that induces strong network bursting ${ }^{11-13,26}$ among electrically coupled HMs (Figure 8a). This phenomenon elicits excessive $\mathrm{Ca}^{2+}$ influx, which depolarizes the neuronal membrane potential to activate further $\mathrm{Ca}^{2+}$ influx ${ }^{49,50}$ and intracellular second messengers in a death cell cascade. ${ }^{51,52}$ The role by mitochondria in $\mathrm{Ca}^{2+}$ buffering may lead to mitochondrial membrane depolarization ${ }^{49,50,53}$ and perturbation of the respiratory chain. ${ }^{49,50}$ This process is compounded by ROS-evoked oxidative stress. ${ }^{13,54,55}$ In this vicious sequence, cell damage is extended via gap junctions ${ }^{17,27,56}$ activated by ROS. ${ }^{37}$

To contrast excitotoxic damage, a potential device is activation of $n A C h R s$ expressed on interneurons and HMs. ${ }^{13,14,20,57}$ $\mathrm{nAChRs}$ operate through a cycle of activation, desensitization and reactivation ${ }^{58}$ that, in the case of brainstem synaptic transmission with diffuse inputs impinging on $\mathrm{HMs}$, include early facilitation of glutamate release followed by depression, whereas synaptic inhibition is enhanced ${ }^{13,20}$ (Figure $8 b$ ). Direct activation of $n A C h R s$ on motoneurons reduces $R O S$ production, enhances Hsp70 expression and uncouples Cx36-mediated intercellular communication. The mechanism linking $n A C h R$ activation to inhibition of $\mathrm{Cx} 36$ activity will require future investigation. We can posit that, as nicotine enhances protein kinase C (PKC) ${ }^{59-61}$ PKC-mediated connexin phosphorylation is a putative process to reduce gap junction-dependent communication. ${ }^{62}$ Finally, our data do not intend to support a neuroprotecting role of smoking, rather to prompt a strategy for further investigation of inhibiting motoneuron disease in vitro and in vivo with novel tools to stimulate $\mathrm{nAChRs}$.

\section{Materials and Methods}

Ethical approval. All experiments were performed following the ethical guidelines for the use and the care of laboratory animals of National Institutes of Health. The Scuola Internazionale Superiore di Studi Avanzati (SISSA) ethics committee (prot. 3599, 28 May 2012) approved all treatment protocols, which were in agreement with the European Union rules for animal experimentation. We made all the effort to minimize the use and the suffering of the animals, and reduce their number for experimentation.

Slice preparation and drug application protocols. Experiments were carried out on neonatal Wistar rats (postnatal days 1-6; P1-P6), rapidly decapitated under i.p. urethane anesthesia ( $10 \%$ solution, $0.1 \mathrm{ml}$ injection volume). Brainstems were removed in continuously carbogenated $\left(95 \% \mathrm{O}_{2}\right.$ and $\left.5 \% \mathrm{CO}_{2}\right)$ ice-cold Krebs solution containing (in $\mathrm{mM}$ ): $130 \mathrm{NaCl}, 3 \mathrm{KCl}, 1.5 \mathrm{NaH}_{2} \mathrm{PO}_{4}, 1 \mathrm{CaCl}_{2}, 5 \mathrm{MgCl}_{2}, 25$ $\mathrm{NaHCO}_{3}$ and 18.5 glucose (pH 7.4; 300-330 mOsm/l). For $\mathrm{Ca}^{2+}$ imaging and immunohistochemical experiments, slices $(270-450 \mu \mathrm{m}$ thick) containing the nucleus hypoglossus were immediately cut with a vibrating tissue slicer (Leica VT 1000S, Wetzlar, Germany). Slices (or intact brainstems for molecular biology) were then rapidly transferred to an incubation chamber for $20 \mathrm{~min}$ at $32^{\circ} \mathrm{C}$ and then recovered for $10 \mathrm{~min}$ at room temperature. Details of the experimental procedure were previously published. ${ }^{12,63}$

With the exception of slices for the calcium-imaging technique, samples were subsequently incubated for $4 \mathrm{~h}$ at room temperature in continuously carbogenated Krebs solution (sham), TBOA (50 $\mu$ M; Sigma-Aldrich, St. Louis, MO, USA), TBOA + nicotine $(10 \mu \mathrm{M}$; Sigma-Aldrich), nicotine, or TBOA + carbenoxolone $(200 \mu \mathrm{M}$; Sigma-Aldrich) and processed as indicated later. Experiments were run in parallel to minimize bias.

Intracellular $\mathrm{Ca}^{2+}$ imaging $\left[\mathrm{Ca}^{2+}\right]_{\mathrm{i}}$. In accordance with formerly described protocols, ${ }^{12,64}$ slices $\left(270 \mu \mathrm{m}\right.$ thick) were loaded with the fluorescent $\mathrm{Ca}^{2+}$ dye
Fluo-3 AM ( $4 \mu \mathrm{M}$, Molecular Probes, Invitrogen, Carlsbad, CA, USA) for $1 \mathrm{~h}$ in continuously carbogenated Krebs solution. After 30-min wash, samples were transferred into the recording chamber of the Nikon Eclipse T1 microscope (Nikon, Tokyo, Japan), where the nuclei hypoglossi were identified with a 40x objective (aperture 0.60). Drug concentrations were chosen on the basis of previous reports ${ }^{12,13}$ and applied acutely in accordance with the following protocols (10 min): TBOA $(50 \mu \mathrm{M})$, nicotine $(10 \mu \mathrm{M})+$ TBOA $(50 \mu \mathrm{M})$; carbenoxolone $(200 \mu \mathrm{M})+$ TBOA $(50 \mu \mathrm{M}) . \mathrm{Ca}^{2+}$ fluorescent emission was excited at a fixed wavelength of $488 \mathrm{~nm}$ generated by a Nikon intensilight C-HGFI lamp (Nikon) and detected with the digital CMOS camera ORCA-Flash 4.0 (Hamamatsu Photonic, Hamamatsu City, Japan). Images were acquired with the Fiji software (ImageJ, Wayne Rasband, National Institute of Health, Bethesda, MD, USA ${ }^{65}$ with $150 \mathrm{~ms}$ exposure time. In each slice, a small region of interest (ROI) was placed over about 30 randomly distributed motoneurons easily recognizable for their somatic diameter (>20 $\mu \mathrm{m})$. Traces extrapolated with Igor Pro software (version 6.37, Wavemetrics, Lake Oswego, OR, USA) were analyzed with the software Clampfit 10.0 (Molecular Devices Corporation, Sunnyvale, $\mathrm{CA}, \mathrm{USA}) . \mathrm{Ca}^{2+}$ transients were analyzed if events had a duration $<20 \mathrm{~s}$ and a rise phase faster than the decay. Transients were expressed as $\Delta \mathrm{F} / \mathrm{F}_{0}$, the amplitude fractional increase, where $\Delta \mathrm{F}$ is the fluorescence rise over baseline, and $\mathrm{F}_{0}$ the baseline fluorescence level; $\left[\mathrm{Ca}^{2+}\right]_{i}$ elevations were considered significant when they exceeded five times the noise S.D. ${ }^{66,67}$

Immunohistochemistry. At the end of 4-h experiments, slices were fixed in PBS containing $4 \%$ paraformaldehyde for $4 \mathrm{~h}$ at $4{ }^{\circ} \mathrm{C}$, treated for cryoprotection in $30 \%$ sucrose for $72 \mathrm{~h}$ at $4{ }^{\circ} \mathrm{C}$, and finally frozen for at least $12 \mathrm{~h}$ in an embedding mounting medium. Embedded slices were then cut with a cryostat in $30 \mu \mathrm{m}$ tissue sections. Samples were blocked (in a PBS-based solution containing: 10\% normal goat serum, $50 \% \mathrm{BSA}$ and $3 \%$ Triton $\mathrm{X}-100$ ) for $2 \mathrm{~h}$ at room temperature and incubated overnight at $4{ }^{\circ} \mathrm{C}$ with the primary antibodies anti-SMI 32 (mouse monoclonal, 1:200 dilution; cat. \#: 801701; BioLegend, San Diego, CA, USA; for validation see Nani et al. ${ }^{63}$ ), anti-CX36 (rabbit polyclonal, 1:300 dilution; cat. \#: ACC-209; Alomone, Jerusalem, Israel), ${ }^{29}$ anti-Panx1 (rabbit polyclonal, 1:300 dilution; cat. \#: ACC-234; Alomone) ${ }^{68}$ or anti-AIF (rabbit polyclonal, 1:200 dilution; cat. \#: AB16501; Millipore, Billerica, MA, USA). ${ }^{69}$ AlexaFluor 488 and 594 (1:500 dilution; Life Technologies, Carlsbad, CA, USA) were used as secondary antibodies and applied for $2 \mathrm{~h}$ at room temperature. Antibodies were diluted in an antibody PBS-based solution containing: $2 \%$ normal goat serum, 10\% BSA and $1 \%$ Triton $X-100$. After secondary antibody incubation, slices were rinsed and stained with the DNA dye DAPI diluted in PBS (1:1 000; Sigma-Aldrich), for $20 \mathrm{~min}$ at room temperature. To reduce fading, slices were mounted with fluorescence mounting medium (Dako, Glostrup, Denmark) and images acquired by either a Zeiss Axioskop2 microscope (20x; Oberkochen, Germany) or a confocal Nikon microscope (40x in oil) with $1 \mu \mathrm{m} \mathrm{z}$ sectioning. Images were analyzed with the Volocity software (PerkinElmer, Waltham, MA, USA).

Western blot. Analysis of quantitative and qualitative protein expression was performed with a standard western blot technique on whole brainstem treated as described above in accordance with the previously published protocol. ${ }^{70}$ Total lysates, cytoplasmic and membrane fractions were analyzed. Total lysates were obtained by homogenizing samples in CHAPS buffer solution (0.5\% CHAPS, $50 \mathrm{mM}$ Tris $\mathrm{pH} 7.5,1 \mathrm{mM}$ EDTA, $150 \mathrm{mM} \mathrm{NaCl}, 10 \%$ glycerol plus protease inhibitors mixture and reducing agents; Complete, Roche Applied Science, Basel, Switzerland; and Sigma-Aldrich). A hypotonic lysis buffer (10 mM HEPES pH 7.9 with $1.5 \mathrm{mM} \mathrm{MgCl}_{2}$ and $10 \mathrm{mM} \mathrm{KCl}$ plus protease inhibitors mixture and reducing agents) was used to process samples for membrane and cytoplasmic extraction, which were then centrifuged for 5 min at 4000 r.p.m. at $4{ }^{\circ} \mathrm{C}$ and the supernatant transferred to ultracentrifuge tubes for centrifugation (1 h) at $100000 \mathrm{~g}$. Cytoplasmic proteins were considered those in the supernant, whereas the pellet was formed by membrane proteins, which were re-suspended in the extraction buffer $(20 \mathrm{mM}$ HEPES pH 7.9, with $1.5 \mathrm{mM} \mathrm{MgCl}_{2}, 0.2 \mathrm{mM}$ EDTA, $25 \%$ glycerol, $1 \%$ SDS plus protease inhibitors mixture and reducing agents). Samples were then immunoblotted with rabbit anti-Cx36 (1:200, Alomone), rabbit anti-Panx1 (1:400, Alomone), mouse anti-Hsp70 (1:5000, Abcam, Cambridge, UK), mouse anti- $\beta$-actin (1:2000, Sigma-Aldrich), mouse anti- $\beta$-tubulin (1:2000, Sigma-Aldrich), or mouse antisynaptophysin (1:10 000, Millipore) antibodies. As both Cx36 and Panx1 encode consensus sites for phosphorylation and glycosilation, it is, thus, common to observe more than one band in the immunoblotting gels ${ }^{45,71}$ as reported in this study as well. The enhanced chemiluminescence light system (ECL, Amersham Bioscience, Piscataway, NJ, USA) was used to detect signals recorded with the 
digital imaging system Alliance 4.7 (UVltech, Cambridge, UK) and quantified with the software Alliance LD2-77-WL (UVItec).

Real-time PCR. PCR experiments were performed on total RNA isolated from tissues, treated as described above, using the Triazol reagent (Invitrogen). RNasefree DNase (Ambion, Austin, TX, USA) was used for RNA extraction and cDNA was purified using the RNeasy Mini Kit (Qiagen, Hilden, Germany), according to the respective manufacturer's instructions. Single-strand cDNA samples were obtained using the iScriptcDNA Synthesis Kit (Bio-Rad, Hercules, CA, USA) from at least $20 \mathrm{ng}$ of purified RNA. To determine mRNA expression, the following primers were used: (1) Cx36: forward, 5'-ATACAGGTGTGAATGAGGGAGGATG-3', reverse, 5'TGGAGGGTGTTACAGATGAAAGAGG-3',72 (2) Actb: forward, 5'-GTGGGGCGCC CCGGCACCA-3', reverse, $5^{\prime}$-CTCCTTAATGTCACGCACGATTT- $3^{\prime} ;{ }^{73}$ (3) Hprt: forward, 5'-TCCTCATGGACTGATTATGGACA-3', reverse, 5'-TAATCCAGCAGG TCAGCAAAGA-3,; $3^{\prime 74}$ (4) Rpl13A: forward, $5^{\prime}$-TCCTCATGGACTGATTATGGA CA-3', reverse, $5^{\prime}$-TAATCCAGCAGGTCAGCAAAGA-3'. ${ }^{74}$ The new synthesized CDNA was amplified using the oligonucleotide primer listed above, the nucleic acid stain iQ SYBER Green Supermix (Bio-Rad) and an iCycler IQ Real-time PCR System (Bio-Rad).

Statistics. Results were expressed as means \pm S.E.M. and collected from at least three different experiments, where $n$ refers to the number of slices or brainstems for each independent experiment, as indicated, and $N$ refers to the number of times an experiment was repeated. Using the standard software SigmaStat 3.5 (Systat Software, Inc., Chicago, IL, USA), we first run an ANOVA test and the normality test to discriminate between parametric and non-parametric data. Subsequently, as directed by the software, the Mann-Whitney test was used for comparing two non-parametric groups. Multiple groups were first analyzed with the Kruskal-Wallis one-way ANOVA on ranks when data were non-parametric and further analysis was carried out with a software directed test (Dunn's method, HolmSidak method or Tukey test). The use of each test for data analysis is indicated in the corresponding Figure legends. Cumulative probabilities were compared with the Kolmogorov-Smirnov test. To analyze the relation between $\mathrm{Ca}^{2+}$ transient latency and cell topographical distribution, we applied the linear correlation method based on the analysis of deviance. ${ }^{75}$ In this way, we observed that that the regression line latency for the experiments with TBOA alone differed in a significant manner $(P<0.001)$ from the null linear model, that is, the mean value latency $=36.60$. Thus, the regression line appears to be the minimal adequate model. ${ }^{76}$ Groups of data were accepted as statistically different if $P \leq 0.05$.

\section{Conflict of Interest}

The authors declare no conflict of interest.

Acknowledgements. This work was supported by an intramural SISSA grant. We thank Dr Nicola Secomandi for help with calcium imaging experimental setting and videos; Dr Maura Barbisin for the help with cytoplasmic and membrane extractions; and Dr Massimo Borelli for helpful suggestions with statistical analysis. $\mathrm{RR}$ is the recipient of a research fellowship supported by the grant PRIN-MIUR no. 2012MYESZW.

1. Orsini M, Oliveira AB, Nascimento OJM, Reis CHM, Leite MAA, de Souza JA et al. Amyotrophic lateral sclerosis: new perspectives and update. Neurol Int 2015; 7: 5885.

2. Kühnlein P, Gdynia H-J, Sperfeld A-D, Lindner-Pfleghar B, Ludolph AC, Prosiegel M et al. Diagnosis and treatment of bulbar symptoms in amyotrophic lateral sclerosis. Nat Clin Pract Neurol 2008; 4: 366-374.

3. Ladewig T, Kloppenburg P, Lalley PM, Zipfel WR, Webb WW, Keller BU. Spatial profiles of store-dependent calcium release in motoneurones of the nucleus hypoglossus from newborn mouse. J Physiol 2003; 547: 775-787.

4. Laslo P, Lipski J, Nicholson LF, Miles GB, Funk GD. GluR2 AMPA receptor subunit expression in motoneurons at low and high risk for degeneration in amyotrophic lateral sclerosis. Exp Neurol 2001; 169: 461-471.

5. Rothstein JD, Martin LJ, Kuncl RW. Decreased glutamate transport by the brain and spinal cord in amyotrophic lateral sclerosis. N Engl J Med 1992; 326: 1464-1468.

6. Cleveland DW, Rothstein JD. From Charcot to Lou Gehrig: deciphering selective motor neuron death in ALS. Nat Rev Neurosci 2001; 2: 806-819.

7. Spreux-Varoquaux O, Bensimon G, Lacomblez L, Salachas F, Pradat PF, Le Forestier $N$ et al. Glutamate levels in cerebrospinal fluid in amyotrophic lateral sclerosis: a reappraisal using a new HPLC method with coulometric detection in a large cohort of patients. J Neurol Sci 2002; 193: 73-78.

8. Swash M, Ingram D. Preclinical and subclinical events in motor neuron disease. J Neurol Neurosurg Psychiatry 1988; 51: 165-168.

9. Kiernan MC, Vucic S, Cheah BC, Turner MR, Eisen A, Hardiman O et al. Amyotrophic lateral sclerosis. Lancet 2011; 377: 942-955.

10. Cifra A, Nani F, Nistri A. Respiratory motoneurons and pathological conditions: lessons from hypoglossal motoneurons challenged by excitotoxic or oxidative stress. Respir Physiol Neurobiol 2011; 179: 89-96.

11. Cifra A, Nani F, Nistri A. Riluzole is a potent drug to protect neonatal rat hypoglossal motoneurons in vitro from excitotoxicity due to glutamate uptake block. Eur J Neurosci 2011; 33: 899-913.

12. Sharifullina $E$, Nistri A. Glutamate uptake block triggers deadly rhythmic bursting of neonatal rat hypoglossal motoneurons. J Physiol 2006; 572: 407-423.

13. Corsini S, Tortora M, Nistri A. Nicotinic receptor activation contrasts pathophysiological bursting and neurodegeneration evoked by glutamate uptake block on rat hypoglossal motoneurons. J Physiol 2016; 594: 6777-6798.

14. Tortora M, Corsini S, Nistri A. Nicotinic receptors modulate the onset of reactive oxygen species production and mitochondrial dysfunction evoked by glutamate uptake block in the rat hypoglossal nucleus. Neurosci Lett 2017; 639: 43-48.

15. Feldman JL, Del Negro CA. Looking for inspiration: new perspectives on respiratory rhythm. Nat Rev Neurosci 2006; 7: 232-242.

16. Feldman JL, Del Negro CA, Gray PA. Understanding the rhythm of breathing: so near, yet so far. Annu Rev Physiol 2013; 75: 423-452.

17. Moore KB, O'Brien J. Connexins in neurons and glia: targets for intervention in disease and injury. Neural Regen Res 2015; 10: 1013-1017.

18. Vinken M. Introduction: connexins, pannexins and their channels as gatekeepers of organ physiology. Cell Mol Life Sci 2015; 72: 2775-2778.

19. Esseltine JL, Laird DW. Next-generation connexin and pannexin cell biology. Trends Cell Biol 2016; 26: 944-955.

20. Quitadamo C, Fabbretti E, Lamanauskas N, Nistri A. Activation and desensitization of neuronal nicotinic receptors modulate glutamatergic transmission on neonatal rat hypoglossal motoneurons. Eur J Neurosci 2005; 22: 2723-2734.

21. Haussig S, Schubert A, Mohr F-W, Dhein S. Sub-chronic nicotine exposure induces intercellular communication failure and differential down-regulation of connexins in cultured human endothelial cells. Atherosclerosis 2008; 196: 210-218.

22. Tsai C-H, Yeh H-I, Tian T-Y, Lee Y-N, Lu C-S, Ko Y-S. Down-regulating effect of nicotine on connexin43 gap junctions in human umbilical vein endothelial cells is attenuated by statins. Eur J Cell Biol 2004; 82: 589-595.

23. Davidson JS, Baumgarten IM. Glycyrrhetinic acid derivatives: a novel class of inhibitors of gap-junctional intercellular communication. Structure-activity relationships. J Pharmacol Exp Ther 1988; 246: 1104-1107.

24. Shabbir A, Bianchetti E, Cargonja R, Petrovic A, Mladinic M, Pilipović K et al. Role of HSP70 in motoneuron survival after excitotoxic stress in a rat spinal cord injury model in vitro. Eur $J$ Neurosci 2015; 42: 3054-3065.

25. Bianchetti $E$, Mladinic $M$, Nistri A. Mechanisms underlying cell death in ischemia-like damage to the rat spinal cord in vitro. Cell Death Dis 2013; 4: e707.

26. Sharifullina E, Ostroumov K, Nistri A. Metabotropic glutamate receptor activity induces a novel oscillatory pattern in neonatal rat hypoglossal motoneurones. J Physiol 2005; 563: 139-159.

27. Belousov AB, Fontes JD. Neuronal gap junction coupling as the primary determinant of the extent of glutamate-mediated excitotoxicity. J Neural Transm 2014; 121: 837-846.

28. Hilgen G, von Maltzahn J, Willecke K, Weiler R, Dedek K. Subcellular distribution of connexin45 in OFF bipolar cells of the mouse retina. J Comp Neurol 2011; 519: 433-450.

29. Marina N, Becker DL, Gilbey MP. Immunohistochemical detection of connexin36 in sympathetic preganglionic and somatic motoneurons in the adult rat. Auton Neurosci Basic Clin 2008; 139: 15-23.

30. Belluardo N, Mudò G, Trovato-Salinaro A, Le Gurun S, Charollais A, Serre-Beinier V et al. Expression of connexin36 in the adult and developing rat brain. Brain Res 2000; 865: 121-138.

31. Ravagnan L, Gurbuxani S, Susin SA, Maisse C, Daugas E, Zamzami N et al. Heat-shock protein 70 antagonizes apoptosis-inducing factor. Nat Cell Biol 2001; 3: 839-843.

32. Matsunaga T, Kohsaka H, Nose A. Gap junction-mediated signaling from motor neurons regulates motor generation in the central circuits of larval Drosophila. $J$ Neurosci 2017; 37: 2045-2060.

33. Tresch MC, Kiehn O. Synchronization of motor neurons during locomotion in the neonatal rat: predictors and mechanisms. J Neurosci 2002; 22: 9997-10008.

34. Decrock E, Vinken M, De Vuyst E, Krysko DV, D’Herde K, Vanhaecke T et al. Connexinrelated signaling in cell death: to live or let die? Cell Death Differ 2009; 16: 524-536.

35. Peracchia $\mathrm{C}$. Chemical gating of gap junction channels: roles of calcium, $\mathrm{pH}$ and calmodulin. Biochim Biophys Acta 2004; 1662: 61-80.

36. Lampe PD, Lau AF. The effects of connexin phosphorylation on gap junctional communication. Int J Biochem Cell Biol 2004; 36: 1171-1186.

37. Ramachandran S, Xie L-H, John SA, Subramaniam S, Lal R. A novel role for connexin hemichannel in oxidative stress and smoking-induced cell injury. PLOS ONE 2007; 2: e712.

38. Ye Z-C, Wyeth MS, Baltan-Tekkok S, Ransom BR. Functional hemichannels in astrocytes: a novel mechanism of glutamate release. J Neurosci 2003; 23: 3588-3596. 
39. Decrock E, De Vuyst E, Vinken M, Van Moorhem M, Vranckx K, Wang N et al. Connexin 43 hemichannels contribute to the propagation of apoptotic cell death in a rat C6 glioma cell model. Cell Death Differ 2008; 16: 151-163.

40. Kalvelyte A, Imbrasaite A, Bukauskiene A, Verselis VK, Bukauskas FF. Connexins and apoptotic transformation. Biochem Pharmacol 2003; 66: 1661-1672.

41. Denuc A, Núñez E, Calvo E, Loureiro M, Miro-Casas E, Guarás A et al. New protein-protein interactions of mitochondrial connexin 43 in mouse heart. J Cell Mol Med 2016; 20: 794-803.

42. Vaccari JC deR, Corriveau RA, Belousov AB. Gap junctions are required for NMDA receptor-dependent cell death in developing neurons. J Neurophysiol 2007; 98: 2878-2886.

43. Wang HY, Lin Y-P, Mitchell CK, Ram S, O'Brien J. Two-color fluorescent analysis of connexin 36 turnover: relationship to functional plasticity. J Cell Sci 2015; 128: 3888-3897.

44. Zhang L, Li Y-M, Jing Y-H, Wang S-Y, Song Y-F, Yin J. Protective effects of carbenoxolone are associated with attenuation of oxidative stress in ischemic brain injury. Neurosci Bull 2013; 29: 311-320.

45. Penuela S, Bhalla R, Gong X-Q, Cowan KN, Celetti SJ, Cowan BJ et al. Pannexin 1 and pannexin 3 are glycoproteins that exhibit many distinct characteristics from the connexin family of gap junction proteins. J Cell Sci 2007; 120: 3772-3783.

46. Canoz O, Gunes T, Deniz K, Akgun H, Balkanli S. Perinatal expression of HSP70 and VEGF in neonatal rat lung vessels exposed to nicotine during gestation. APMIS 2006; 114: $10-14$.

47. Hahn GM, Shiu EC, Auger EA. Mammalian stress proteins HSP70 and HSP28 coinduced by nicotine and either ethanol or heat. Mol Cell Biol 1991; 11: 6034-6040.

48. Shimamoto K, Lebrun B, Yasuda-Kamatani Y, Sakaitani M, Shigeri Y, Yumoto N et al. DLthreo- $\beta$-benzyloxyaspartate, a potent blocker of excitatory amino acid transporters. $\mathrm{Mol}$ Pharmacol 1998; 53: 195-201.

49. Gleichmann M, Collis LP, Smith PJS, Mattson MP. Simultaneous single neuron recording of $\mathrm{O}_{2}$ consumption, $\left[\mathrm{Ca}^{2+}\right]_{i}$ and mitochondrial membrane potential in glutamate toxicity. J Neurochem 2009; 109: 644-655

50. Rueda CB, Llorente-Folch I, Traba J, Amigo I, Gonzalez-Sanchez P, Contreras L et al. Glutamate excitotoxicity and $\mathrm{Ca}^{2+}$-regulation of respiration: role of the $\mathrm{Ca}^{2+}$ activated mitochondrial transporters (CaMCs). Biochim Biophys Acta 2016; 1857: 1158-1166.

51. Connolly NMC, Prehn JHM. The metabolic response to excitotoxicity - lessons from single-cell imaging. J Bioenerg Biomembr 2014; 47: 75-88.

52. Kritis AA, Stamoula EG, Paniskaki KA, Vavilis TD. Researching glutamate - induced cytotoxicity in different cell lines: a comparative/collective analysis/study. Front Cell Neurosci 2015; 9: 91.

53. Calvo M, Sanz-Blasco S, Caballero E, Villalobos C, Núñez L. Susceptibility to excitotoxicity in aged hippocampal cultures and neuroprotection by non-steroidal anti-inflammatory drugs: role of mitochondrial calcium. J Neurochem 2015; 132: 403-417

54. Nguyen D, Alavi MV, Kim K-Y, Kang T, Scott RT, Noh YH et al. A new vicious cycle involving glutamate excitotoxicity, oxidative stress and mitochondrial dynamics. Cell Death Dis 2011; 2: e240

55. Yan M, Zhu W, Zheng X, Li Y, Tang L, Lu B et al. Effect of glutamate on lysosomal membrane permeabilization in primary cultured cortical neurons. Mol Med Rep 2016; 13: 2499-2505.

56. Belousov AB. Novel model for the mechanisms of glutamate-dependent excitotoxicity: role of neuronal gap junctions. Brain Res 2012; 1487: 123-130.

57. Machaalani R, Kashi PK, Waters KA. Distribution of nicotinic acetylcholine receptor subunits alpha7 and beta2 in the human brainstem and hippocampal formation. J Chem Neuroanat 2010; 40: 223-231.

58. Giniatullin R, Nistri A, Yakel JL. Desensitization of nicotinic ACh receptors: shaping cholinergic signaling. Trends Neurosci 2005; 28: 371-378.

59. Koide M, Nishizawa S, Yamamoto S, Yamaguchi M, Namba H, Terakawa S. Nicotine exposure, mimicked smoking, directly and indirectly enhanced protein kinase $\mathrm{C}$ activity in isolated canine basilar artery, resulting in enhancement of arterial contraction. J Cereb Blood Flow Metab 2005; 25: 292-301.
60. Tuominen RK, McMillian MK, Ye H, Stachowiak MK, Hudson PM, Hong JS. Long term activation of protein kinase $\mathrm{C}$ by nicotine in bovine adrenal chromaffin cells. J Neurochem 1992; 58: 1652-1658.

61. Messing RO, Stevens AM, Kiyasu E, Sneade AB. Nicotinic and muscarinic agonists stimulate rapid protein kinase C translocation in PC12 cells. J Neurosci 1989; 9: 507-512.

62. Pogoda K, Kameritsch P, Retamal MA, Vega JL. Regulation of gap junction channels and hemichannels by phosphorylation and redox changes: a revision. BMC Cell Biol 2016; $17: 11$.

63. Nani F, Cifra A, Nistri A. Transient oxidative stress evokes early changes in the functional properties of neonatal rat hypoglossal motoneurons in vitro. Eur J Neurosci 2010; 31 951-966.

64. Fabbro A, Skorinkin A, Grandolfo M, Nistri A, Giniatullin R. Quantal release of ATP from clusters of PC12 cells. J Physiol 2004; 560: 505-517.

65. Schindelin J, Arganda-Carreras I, Frise E, Kaynig V, Longair M, Pietzsch T et al. Fiji: an open-source platform for biological-image analysis. Nat Methods 2012; 9: 676-682.

66. Rauti R, Lozano N, León V, Scaini D, Musto M, Rago I et al. Graphene oxide nanosheets reshape synaptic function in cultured brain networks. ACS Nano 2016; 10: 4459-4471.

67. Bosi S, Rauti R, Laishram J, Turco A, Lonardoni D, Nieus T et al. From 2D to 3D: nove nanostructured scaffolds to investigate signalling in reconstructed neuronal networks. SCi Rep 2015; 5: 9562

68. Beckel JM, Daugherty SL, Tyagi P, Wolf-Johnston AS, Birder LA, Mitchell CH et al. Pannexin 1 channels mediate the release of ATP into the lumen of the rat urinary bladder. $J$ Physio 2015; 593: 1857-1871.

69. Kanungo AK, Hao Z, Elia AJ, Mak TW, Henderson JT. Inhibition of apoptosome activation protects injured motor neurons from cell death. J Biol Chem 2008; 283: 22105-22112.

70. Mladinic M, Bianchetti E, Dekanic A, Mazzone GL, Nistri A. ATF3 is a novel nuclear marke for migrating ependymal stem cells in the rat spinal cord. Stem Cell Res 2014; 12: 815-827.

71. Solan JL, Lampe PD. Connexin phosphorylation as a regulatory event linked to gap junction channel assembly. Biochim Biophys Acta 2005; 1711: 154-163.

72. Haefliger J-A, Martin D, Favre D, Petremand Y, Mazzolai L, Abderrahmani A et al. Reduction of connexin36 content by ICER-1 contributes to insulin-secreting cells apoptosis induced by oxidized LDL particles. PLOS ONE 2013; 8: e55198.

73. Wang Z, Si L-Y. Hypoxia-inducible factor-1 $\alpha$ and vascular endothelial growth factor in the cardioprotective effects of intermittent hypoxia in rats. Ups J Med Sci 2013; 118: 65-74.

74. Yao L, Chen X, Tian Y, Lu H, Zhang P, Shi $Q$ et al. Selection of housekeeping genes for normalization of RT-PCR in hypoxic neural stem cells of rat in vitro. Mol Biol Rep 2011; 39 : $569-576$.

75. Faraway JJ (eds). Extending the Linear Model with R. Chapman \& Hall/CRC press: Boca Raton London, New York, NY, USA, 2006.

76. Crawley MJ (eds). Statistics: An Introduction using R. John Wiley \& Sons press: Chichester UK, 2005

(c) (i) Cell Death and Disease is an open-access journal published by Nature Publishing Group. This work is licensed under a Creative Commons Attribution 4.0 International License. The images or other third party material in this article are included in the article's Creative Commons license, unless indicated otherwise in the credit line; if the material is not included under the Creative Commons license, users will need to obtain permission from the license holder to reproduce the material. To view a copy of this license, visit http://creativecommons.org/licenses/by/4.0/

(C) The Author(s) 2017

Supplementary Information accompanies this paper on Cell Death and Disease website (http://www.nature.com/cddis) 